\title{
Mathematical models of hydrocyclone performance in various copper ores preparation circuits
}

\author{
Tomasz Niedoba ${ }^{1, a}$, Tadeusz Tumidajski ${ }^{1}$, and Agnieszka Surowiak ${ }^{1}$ \\ ${ }^{1}$ AGH University of Science and Technology, Faculty of Mining and Geoengineering, Department of Environmental \\ Engineering and Mineral Processing, al. Mickiewicza 30, 30-059 Krakow, Poland
}

\begin{abstract}
Copper ores located in the Lubin-Glogow Copper Basin contain three main lithological fractions: sandstone, carbonate and shale. This fact is the basic problem of organization and conducting ore preparation to flotation. The existing circuit of feed preparation contains (in ZG Rudna) five classification nodes of hydrocyclones which fit for various purposes. The elaboration of concept of monitoring work of these nodes should be based on appropriate mathematical models of process. It was decided that either regressive or non-dimensional models that is classification according to Svarovsky, and particularly Plitt's, will be suitable, in the aspects of $d_{50}$ and partition sharpness. Errors resulting from determination of the features being part of the equations were also important. In this paper the errors were divided into technical and technological. The issue of experiments organization (mineralogical investigation connected with each classification node) was also addressed. It is obvious that each classification node must obtain its characteristics because of various comminution products directed to classification.
\end{abstract}

\section{Introduction}

It can be accepted that the basic problem of beneficiation of Polish copper ores is their complex lithological composition (sandstone, carbonate, shale ores) which is indicated by different comminution course, different size of useful minerals incrustations and other useful components contents. Hydrocyclones decide about the course of qualification (direction) of feed particles to flotation which determine also the amount of material being returned back to the process and amount of additionally ground products. Figure 1 presents the circuit with five hydrocyclone batteries. Each one realizes a slightly different purpose and directs overflows to various flotation processes. The determination of strategy of conducting hydrocyclones work is a complex task and must be based on mathematical models of good quality which describe their work. The additional difficulty is the necessity of conducting modeling under industrial conditions by full acceptable changeability of the feed.

Because of practical applications, the interesting ones are models determining size of cut point $d_{50}$ and so-called partition sharpness $s$, which can be accepted as the ratio of $d_{75} / d_{25}$, where $d_{75}, d_{50}$ and $d_{25}$ are the values being determined on the basis of partition curve ( $k$-percentage particles).

${ }^{a}$ Corresponding author: tniedoba@agh.edu.pl 
In present paper the problems related to modeling of hydrocyclones work will be considered presented for Lubin-Glogow Copper Basin (LGOM) because of $d_{50}$ and $s$. Furthermore, the difficulties with including determination of some variables, influence of errors of their determining on quality of models as well ideas on strategy of conducting processes of feed preparation for beneficiation were investigated.

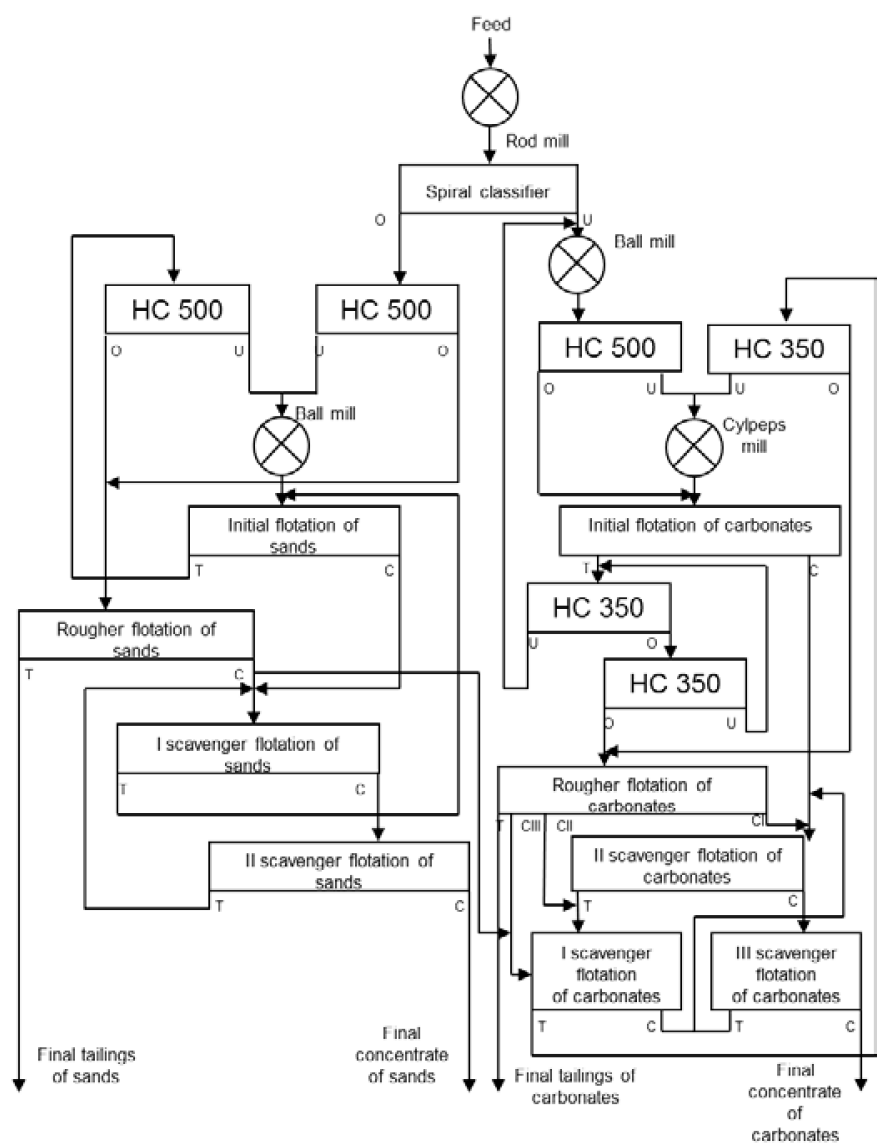

Figure 1. Scheme of beneficiation of material rich in sandstone and carbonate fractions at KGHM Polska Miedz S.A., O/ZWR Region Rudna (U - underflow, $\mathrm{O}$ - overflow, T - tailings, C - concentrate) [5].

\section{General characteristics of Polish copper ores}

As it was mentioned, in area of LGOM, three main copper ores types can be found. Below, the characteristics of individual ores types and their mineralization was discussed [10].

\subsection{Sandstone ore}

Sandstone ore is created mainly by quartz, sandstones of high changeability of sort of binder in which dissipated type of mineralization with sulfide minerals occurs [26]. It consists usually of quartz (75 to $97 \%$ of rock volume) in which size of the material is within $0.04-0.5 \mathrm{~mm}$ (most often $0.08-0.3 \mathrm{~mm}$ ). The particle composition does not change too much in various types of sandstones. However, the composition of binders is differentiated. The clay, carbonate, clay-carbonate and sulfide types of 
binders can be found, while the most often is calcite [16]. Sandstones of clay and clay-carbonate binders are featured usually with high contents of copper sulfides. The typical concentration of $\mathrm{Cu}$ is from 1 to $2 \%$. Sandstones with carbonate binders have high changeability concerning metals sulfides contents, including copper. However, in sandstones with sulfide binders the contents of sulfides oscillates between 0.2 and $1 \%[1,9]$.

Mineralization in the sandstone ore is water-repellent and occurs in spaces between particles. The dominant fraction is $0.098-0.5 \mathrm{~mm}$ being $75 \%$ of weight of ore. Granulation is rather even with the smallest share of the finest particles [11].

\subsection{Shale ore}

The shale ore is located directly above sandstones. The thickness of the shale fraction in the deposit is equal, on average, to about $30 \mathrm{~cm}$. It consists mainly of clay, dolomite, quartz and also organic matter. As a result of changing proportions between main components, two types of shale: clay-dolomite and clay-organic are created [24]. Clay-organic shale, being about $10 \%$ of all shale, contains of $70 \%$ clay minerals, $10 \%$ organic matter, $10-15 \%$ copper sulfide minerals and $5 \%$ carbonates and quartz. This type of shale contains the highest contents of additional elements such as $\mathrm{Ag}, \mathrm{Pb}, \mathrm{Co}, \mathrm{Zn}, \mathrm{Mo}, \mathrm{Ni}$ and As in comparison to other ore types $[2,12]$. Furthermore, clay-dolomite shales consist of about $60 \%$ dolomite, $30 \%$ clay minerals, $5 \%$ organic matter and 5\% copper sulfide minerals. They represent about $90 \%$ of the whole amount of shale fraction occurring in the deposit [13, 26].

The ore mineralization is mainly of vein and lens types [16]. Copper shales have very fine granulation because about $94 \%$ of particles are below $42 \mu \mathrm{m}$ in size, that is about $11.5 \%$ of the weight. The content of the coarsest fraction $(0.14-10 \mathrm{~mm})$ is $37.5 \%$ of the weight [11].

\subsection{Carbonate ore}

The areas of occurrence of the sandstone ore are located in northern and eastern parts of Lubin Malomice and Rudna Regions. Deposits of carbonates dominates mainly in Radwanice East (deposit without sandstone ore) and Polkowice. In the copper deposits located in the Fore-Sudetic Monocline about 140 of minerals were described [25]. The main copper-bearing minerals in the deposit zone are chalcocite, bornite, chalcopyrite, covellite, digenite and tennantite. In the carbonate-shale ores the minerals occur in forms of dissipated particles and aggregates as well as nests and veins. In sandstone, the minerals occur usually in dissipated form being one of the form of either binder or mineral lamination $[3,20]$. In all types of ores, the mineralization with chalcocite is dominant. The additional elements are mainly $\mathrm{Ag}, \mathrm{Au}, \mathrm{Pb}, \mathrm{Co}$, Mo and others. They occur mainly in the form of either isomorphic additions or create their own minerals [1]. Because of a lack of mineralization continuity and high irregularity, these concentrations are not like the deposit fulfilling conditions of economic profitability of its single exploitation. A significant part of precious metals contained in material being delivered from mining plants and processed in a beneficiation plant is transferred to a flotation concentrate and is recovered in pyrometallurgical processes.

Mineralization occurring in the carbonate ore is characteristic because of the presence of coarse particles, from 0.14 to $5 \mathrm{~mm}$, which is about $60 \%$ of the weight, while $7-28 \mu \mathrm{m}$ size fraction is only $3 \%$ of the weight $[11,12,26]$.

\section{Structure of models of hydrocyclone work}

As it was mentioned, the majority of models describing hydrocyclones work is based on such values as cut point $d_{50}$, partition sharpness $s$ and, eventually, flowrate. Svarovsky and Svarovsky [31] made the division of theory and models of hydrocyclones work into seven groups:

- $\quad$ simple fundamental theories; 
- two-phase flow theory;

- crowding theory;

- regression models;

- dimensionless group models;

- analytical flow models;

- numerical simulations of flow.

Without consideration of rules of this division it is worthy to state that, from practical point of view, it is possible to achieve regression and so-called dimensionless models under industrial conditions. It can be underlined that analytical models of flows and their simulations are future solutions of issues considered in this paper. This idea is in accordance with the one presented in [30, 31].

Currently, for example, simulations CFD (Computational Fluid Dynamics) are applied to determine parameters of equations by means of special software like package FLUENT. Obtaining of certain recommendations for monitoring strategy from these models is very difficult [22, 23, 32]. According to many authors $[7,8,14,15,17,19,21,27,28,29,30,31,33]$ the cut point and other characteristics of hydrocyclone work depend on many technical parameters of device and feed features. Generally, it is accepted that exponential and multiplied models are in use. The generalization of the research is the JKTech model [18]:

where:

$$
d_{50}=K_{D O}\left(\frac{D_{O}}{D_{C}}\right)^{\alpha_{1}}\left(\frac{D_{U}}{D_{C}}\right)^{\alpha_{2}}\left(\frac{P}{\rho_{S L g D_{C}}}\right)^{\alpha_{3}}\left(\frac{D_{I}}{D_{C}}\right)^{\alpha_{4}}\left(\frac{L_{C Y L}}{D_{C}}\right)^{\alpha_{5}} \Theta^{\alpha_{6}} H_{S}{ }^{\alpha_{7}}
$$

$P$ - feed pressure $[\mathrm{kPa}] ; g$-acceleration due to gravity; $\Theta$ - cone angle, $\left[{ }^{\circ}\right] ; H_{S}$ - hindered settling factor; $K_{D O}$ - material constant depending on the specific gravity and size of particles in the feed, $D_{U}$ - underflow diameter $[\mathrm{m}] ; D_{I}$ - inlet diameter $[\mathrm{m}] ; D_{O}$ - overflow diameter $[\mathrm{m}] ; L_{C Y L}$ - length of cylindrical section $[\mathrm{m}] ; D_{C}-$ diameter of the cylindrical section $[\mathrm{m}] ; \rho_{S L}-$ feed slurry density $\left[\mathrm{Mg} / \mathrm{m}^{3}\right] ; \alpha_{1}, \ldots, \alpha_{7}$ - parameters of equation to be determined.

Working under laboratory conditions, by classification of sands, Plitt [27] elaborated a general model which was several times modified and adjusted:

$$
d_{50}=\frac{k_{1} D_{C}{ }^{\beta_{1}} D_{I}{ }^{\beta_{2}} D_{O} \beta_{3} \mu^{\beta_{4}} \exp \left(\beta_{5} C_{V S(F)}\right)}{D_{U}{ }^{\beta_{6}} L_{V F}{ }^{\beta_{7}} Q_{V(F)}{ }^{\beta_{8}}\left(\rho_{S}-\rho_{L}\right)^{\beta_{9}}}
$$

where:

$Q_{V(F)}$ - volumetric flowrate of the feed $\left[\mathrm{m}^{3} / \mathrm{s}\right] ; C_{V S(F)}-\%$ of solids by volume in the feed; $\mu$ - liquid viscosity $[\mathrm{mPa} . \mathrm{s}] ; \rho_{S}-$ density of solid $\left[\mathrm{kg} / \mathrm{m}^{3}\right] ; \rho_{L}-$ density of liquid $\left[\mathrm{kg} / \mathrm{m}^{3}\right] ; k_{1}-$ calibration factor; $L_{V F}-$ free vortex height $[\mathrm{m}]$. The other symbols as in the equation (1).

Assuming that partition sharpness $s$ can be defined as $s=\frac{d_{75}}{d_{25}}$, it can be accepted that the mathematical model for $s$ will assume a general form of equation (1) or (2) with correctly determined parameters.

The key issue in modeling of classification process in hydrocyclones is then the problem of determining partition curve for $d_{50}, d_{75}$ and $d_{25}$. By determining $d_{50}$ (partition curve) the Grumbrecht method can be applied which allows elimination of eventual anomalies in shape of obtained curve. To do it the following parameters should be accepted:

$a_{i}-$ share of $i^{\text {th }}$ particle fraction in feed

$b_{i}-$ share of $i^{\text {th }}$ particle fraction in underflow

$c_{i}$ - share of $i^{\text {th }}$ particle fraction in overflow.

If the underflow yield is denoted as $\gamma$, then 


$$
a_{i}=\gamma b_{i}+(1-\gamma) c_{i} .
$$

Because of existing errors of analyses and other disturbances, the sides of Equation (3) will not be equal. By minimizing the differences (squares and sum):

$$
S=\sum\left(a_{i}-\gamma b_{i}-(1-\gamma) c_{i}\right)^{2}
$$

according to the rules of determining extreme, it is obtained that

$$
\gamma=\frac{\sum\left(b_{i}-c_{i}\right)\left(a_{i}-c_{i}\right)}{\sum\left(c_{i}-b_{i}\right)^{2}} .
$$

If $y=A B$, is accepted as simplified version of Plitt's model, where

$$
A=\frac{D_{I}^{\beta_{2}} D_{O}^{\beta_{3}}}{D_{U}^{\beta_{6}}}
$$

and

$$
B=\frac{k_{1} D_{C}{ }^{\beta_{1}} \mu^{\beta_{4}} \exp \left(\beta_{5} C_{V S(F)}\right)}{L_{V F}{ }^{\beta_{7}} Q_{V(F)}{ }^{\beta_{8}}\left(\rho_{S}-\rho_{L}\right)^{\beta_{9}}}
$$

then the certain numerical simulation can be done. Let us assume that $B=$ const and $y=d_{50}=$ certain value. If these assumptions are accepted, then is possible, by changing values of $D_{I}, D_{O}$ and $D_{U}$, to show in what range the value of $d_{50}$ can change. Also, the reverse option can be accepted that $A=$ const, $d_{50}=$ certain value and analogical simulation can be conducted on the basis of changes of the values occurring in part $B$.

In the experiment, the real values of settings for H500 hydrocyclones were accepted and also the limits of the changeability of individual variables in the model were assumed for these, which were qualified to part $A$. Part $B$ was assumed as constant, calculated on the basis of part $A$ and assumed cut point $d_{50}$. The values of parameters $\beta_{1}-\beta_{9}$ were taken from the original Plitt's model and they were shown in Table 1 . The settings and values of cut point occurring from the model were presented in Tables 2 and 3.

Because the recommended cut point in hydrocyclones is particle of size $0.150 \mathrm{~mm}$, such value was accepted as the expected one for the investigated H500hydrocyclone, then the susceptibility of the model to assumed acceptable changes of individual factors was investigated. As the basic cut point sizes, apart from $0.150 \mathrm{~mm}$, the sizes $0.250,0.500,0.600,0.700,0.800,0.900,1.000$ and $1.100 \mathrm{~mm}$ were accepted. Table 3 shows the changeability of these cut points dependably on accepted minimum and maximum settings for variables from part $A$, keeping value of $B$ as constant (presented in Table 1). The value of $k_{1}$ was assumed to be equal to 1 .

Table 1. Values of parameters in initial Plitt's model [7].

\begin{tabular}{|c|c|}
\hline Parameter & Value \\
\hline$\beta_{1}$ & 0.46 \\
\hline$\beta_{2}$ & 0.6 \\
\hline$\beta_{3}$ & 1.21 \\
\hline$\beta_{4}$ & 0.5 \\
\hline$\beta_{5}$ & 0.063 \\
\hline$\beta_{6}$ & 0.71 \\
\hline$\beta_{7}$ & 0.38 \\
\hline$\beta_{8}$ & 0.45 \\
\hline$\beta_{9}$ & 0.5 \\
\hline
\end{tabular}


Table 2. Accepted values of variables in Plitt's model.

\begin{tabular}{|c|c|c|c|c|}
\hline Variable & Units & $\begin{array}{c}\text { Assumed } \\
\text { position }\end{array}$ & $\begin{array}{c}\text { Minimum } \\
\text { position }\end{array}$ & $\begin{array}{c}\text { Maximum } \\
\text { position }\end{array}$ \\
\hline$D_{I}$ & $\mathrm{~mm}$ & 125 & 100 & 150 \\
\hline$D_{O}$ & $\mathrm{~mm}$ & 175 & 150 & 200 \\
\hline$D_{U}$ & $\mathrm{~mm}$ & 60 & 50 & 70 \\
\hline
\end{tabular}

Table 3. Values of cut point.

\begin{tabular}{|c|c|c|c|c|c|c|c|c|c|}
\hline Position & \multicolumn{70}{|c|}{ Cut point $\boldsymbol{d}_{\mathbf{5 0}}[\mathbf{m m}]$} \\
\hline $\begin{array}{c}\text { Assumed } \\
\text { position }\end{array}$ & 0.150 & 0.250 & 0.500 & 0.600 & 0.700 & 0.800 & 0.900 & 1.000 & 1.100 \\
\hline $\begin{array}{c}\text { Minimum } \\
\text { position }\end{array}$ & 0.124 & 0.207 & 0.414 & 0.497 & 0.580 & 0.662 & 0.745 & 0.828 & 0.911 \\
\hline $\begin{array}{c}\text { Maximum } \\
\text { position }\end{array}$ & 0.177 & 0.295 & 0.589 & 0.707 & 0.825 & 0.942 & 1.060 & 1.178 & 1.296 \\
\hline
\end{tabular}

The susceptibility of the model to individual changes of parameters can be observed. The hydrocyclone operator can then adjust these parameters in the way assuring the final effect (appropriate cut point and partition sharpness) to be satisfying one. For example, to achieve smaller cut points, lower diameters of individual nozzles should be taken. However, it has to be remembered that such hydrocyclones require appropriate feed granulation what causes necessity of its appropriate comminution. Furthermore, the entry of Plitt's models require adaptation to the data obtained on other types of hydrocyclones, what will be the issue of further investigations. Also, Plitt's model concerning partition of slurries volume on products should be noticed [28]:

$$
S=\frac{Q_{V(U)}}{Q_{V(O)}}=\frac{k_{2}\left(\frac{D_{U}}{D_{O}}\right)^{\gamma_{1}} L_{V F}{ }^{\gamma_{2}}\left(D_{U}{ }^{2}+D_{O}{ }^{2}\right)^{\gamma_{3}} \exp \left(\gamma_{4} C_{V S(F)}\right) \rho_{S L} \gamma_{7}}{P^{\gamma_{5}} D_{C}{ }^{\gamma_{6}}}
$$

where:

$Q_{V(U)}$ - volumetric flow of underflow $\left[\mathrm{m}^{3} / \mathrm{h}\right] ; Q_{V(O)}-$ volumetric flow of overflow $\left[\mathrm{m}^{3} / \mathrm{h}\right]$. The rest of marks as in equations (1) and (2).

Furthermore, the determination of appropriate pressure $P$ is important.

$$
P=\frac{k_{3} Q_{V(F)} \delta_{1} \exp \left(\delta_{2} C_{V S(F)}\right)}{D_{C}{ }^{\delta_{3}} D_{I}^{\delta_{4}} L_{V F}\left(D_{U}^{2}+D_{O}^{2}\right)^{\delta_{5}}} .
$$

Apart from this, currently it is suitable to use not only one, specific equation, for example, determining cut point size, but a set of equations determining, for example, flowrate, reduced cut point, capacity and partition sharpness. According to [19], the appropriate set of equations gives very good effects of fitting the empirical data.

\section{Problems of modeling of hydrocyclones work under industrial conditions}

The presented models of hydrocyclones work were obtained under laboratory conditions which ensured mainly stability of feed structure and allowed to organize course of experiment in the way maximally flexible. Under industrial conditions (Polish copper ores processing) momentary changes of quality of processed ore change such features as density of slurries, share of individual fractions, share of lithological layers as well density of solids and useful component grade. By modeling 
hydrocyclones work, the basic problem is correct determination of partition curve and especially characteristic values like $d_{50}, d_{25}$ and $d_{75}$. Because of the reasons mentioned above, the collection of representative samples is practically impossible. The application of granulometers, densimeters or other measuring units do not solve the problems in this aspect.

It is worthy to notice that if yields of hydrocyclones products are determined by Grumbrecht's method (complex balance of fractions shares), the possibility of change of fractions shares during realization of separation process must be taken into consideration (blurring of particles during dynamic course of the process) what in connection with analyzes errors may lead to inequalities in balance equations. Errors committed on this stage lead also to errors in determining the value of $d_{50}$ (more generally - course of partition curve).

The determination of the technological values occurring in discussed models is also vitiated by errors and it is obvious that these errors (together with the error of $d_{50}$ ) influence the determined values of parameters of regression $[4,6]$.

The conducted contemplations may be the basis for elaboration of the industrial experiment schedule, which results would be the basis for determination of mathematical model for hydrocyclones.

\section{Conclusions}

If the purpose is to optimize the classification of hydrocyclones during the beneficiation of the Polish copper ores it is necessary to determine mathematical models of hydrocyclones worked under real conditions. Taking into consideration the eventual planned change of hydrocyclones in the circuit, possibility of selecting their parameters and using the models presented in this paper, the course of industrial experiment was proposed with changes of technical and technological values taken into account. The collected data set, by acceptable change of variables (proportionally), will be the basis to conduct calculations and create model of hydrocyclones work (equivalent of Equation 2). The obtained model will create the base of elaborating concept of monitoring the feed preparation circuit determining the values of cut points, flowrates (eventual return flows) and amount of processed feed dependably on various shares of lithological layers. For this purpose the circuit work must be characterized for useful minerals liberation - the samples of the feed and separation products must be collected and the chemical and mineralogical analyses for selected particle fractions must be conducted. These investigations, together with the attempt of determining models of the form presented in Equations 8 and 9 will allow to elaborate the concept of monitoring, to determine the feed flowrate and returned material flowrate. The additional grinding of the products in ball mills and especially in cylpebbs mills lead to sufficient liberation of useful minerals, so the amount of the socalled "hard" particles is lower. The appropriate monitoring of classification products yields and adaptation of the process (amount of the feed) to lithological structure of the ore should increase the recovery and quality of flotation concentrates. Such analyses will provide information which can be used in answering the question connected with algorithms of process monitoring.

The presented indications show how to prepare experiments concerning optimization of the hydrocyclones work. It must be remembered that the whole procedure can be different for various ores types to obtain satisfying results.

\section{References}

1. M. Banas, P. Kijewski, W. Salamon, J. Pieczonka, A. Piestrzynski, in Monograph of KGHM PM SA (KGHM CUPRUM Sp. z o.o. CBR, 214, 2007)

2. M. Banas, W. Mayer, A. Piestrzynski, W. Salomon, Ann. Socie. Geologorum Poloniae, 53(1-4), 13(1982) 
3. A. Bolewski, A. Manecki: Detailed mineralogy (Wydawnictwo Polska Agencja Ekologiczna, Warszawa, 1993)

4. J. M. Czaplicki, Elements of mathematical statistics and their applications in mining and ground works engineering (Wydawnictwo Politechniki Slaskiej, Gliwice, 2011)

5. J. Drzewiecki, J. Butra, A. Kosior, Cuprum, 1, 185 (2008)

6. W.A. Fuller, Measurement Error Models (John Wiley and Sons, New York, 1987)

7. A. Gupta, D.S. Yan, Mineral Processing Design and Operations: An Introduction (Elsevier, 2006)

8. $\quad$ K.T. Hsieh, K. Rajamani, AIChE Journal, 37( 5), 735 (1991)

9. W. Kaczmarek, R. Rozek, Miner. Resour. Manag., 24(4), 129 (2008)

10. E. Kasinska-Pilut, PhD Thesis (AGH Krakow, 2014)

11. P. Kijewski, J. Jarosz, in Accompanying metals in copper ores deposit - state of research and perspectives of their further applications, 21, (1987)

12. H. Kucha, W. Mayer, A. Piestrzynski, Ores and Non-Ferrous Metals, 6, 254 (1982)

13. H. Kucha, Ann. Socie. Geologorum Poloniae, 46(3), 363 (1985)

14. A.J. Lynch, T.C. Rao, Indian J. Technol., 6, 106 (1968)

15. A.J. Lynch, Mineral Crushing and Grinding Circuits: Their Simulation, Optimisation, Design and Control (Elsevier, 1977)

16. W. Mayer, A. Piestrzynski, Mineralogical Works, 75,(1) (1985)

17. K. Nageswararao, AusIMM Proceedings, 300(2), 21 (1995)

18. T.J. Napier-Munn, S. Morrell, R. Morrison, T. Kojovic, Mineral Comminution Circuits Their Operation and Optimisation (JKMRC, 1996)

19. M. Narasimha, A.N. Mainza, P.N. Holtham, M.S. Powell, M.S. Brennan, Int,. J. Miner. Process., 133, 1 (2014)

20. M. Niec, A. Piestrzynski, Monograph of KGHM PM SA, Part II, (Wyd. KGHM CUPRUM Sp. z o.o. CBR, Wroclaw, 167, 2007)

21. A. Nowak, A. Surowiak, Archives of Min. Sci., 58(4), 1209 (2013)

22. E. Nowak, Z. Stegowski, B. Tora, M. Kurzac, in Proceedings of the XXIII International Mineral Processing Congress (Istanbul, 1743, 2006)

23. E. Nowak, Z. Stegowski, Tracers and tracing methods (Warszawa, 62, 2004)

24. S. Oszczepalski, A. Rydzewski, Metalogenous atlas of Zechstein cupriferous series in Poland, (Panstwowy Instytut Geologiczny, Warszawa, 1997)

25. J. Pieczonka, A. Piestrzynski, Miner. Resour. Manag., 22(3), 187 (2006)

26. A. Piestrzynski, Monograph of KGHM PM SA, Part II, (Wyd. KGHM CUPRUM Sp. z o.o. CBR, Wroclaw, 167, 2007)

27. L.R. Plitt, J.A. Finch, B.C. Flintoff, in Proceedings of European Symposium Particle Technology (Amsterdam, 790 1980)

28. L.R. Plitt, CIM Bulletin, 12, 114 (1976)

29. C.M. Scheid, L.A. Calcada, R.S.A. Goncalves, G. Massarani, Brazilian J. Chem. Eng., 30(4) 781 (2013)

30. L. Svarovsky, Hydrocyclones (Holt Rinchart \& Winston, London, 1984)

31. L. Svarovsky, G. Svarovsky, Hydrocyclones, volume II (Svarovsky, 2014)

32. M. Tora, PhD Thesis (Ostrava, (2013)

33. B.A. Wills, T.J. Napier-Munn, An Introduction to the Practical Aspects of Ore Treatment and Mineral Recovery (Butterworth-Heinemann, 2006) 